\title{
Expectant management of incomplete miscarriage, anembryonic pregnancy and early fetal demise: a comparative study
}

\author{
Reshma Sajan K. K. ${ }^{1 *}$, Mumtaz P. ${ }^{2}$, Chandrika C. V. ${ }^{1}$, Abdul Vahab ${ }^{2}$, Hassan Sheikh Imrana
}

${ }^{1}$ Department of Obstetrics and Gynecology, Government Medical College, Palakkad, Kerala, India

${ }^{2}$ Department of Obstetrics and Gynecology, MES Medical College, Perintalmanna, Kerala, India

Received: 10 July 2020

Accepted: 15 July 2020

\section{*Correspondence:}

Dr. Reshma Sajan K. K.,

E-mail: reshma0407@gmail.com

Copyright: $\odot$ the author(s), publisher and licensee Medip Academy. This is an open-access article distributed under the terms of the Creative Commons Attribution Non-Commercial License, which permits unrestricted non-commercial use, distribution, and reproduction in any medium, provided the original work is properly cited.

\section{ABSTRACT}

Background: Expectant management as first line management of early pregnancy miscarriages is less accepted due to failure and increased complications reported in few studies. Proper selection of cases improves outcome of expectant management. Aim of this study was to compare success rate and complications in expectant management in three groups of early pregnancy miscarriages- Incomplete miscarriage, anembryonic pregnancy and early fetal demise.

Methods: Prospective observational study conducted in tertiary care centre for 3 years, including 107 patients with USG confirmed pregnancy miscarriage $<13$ weeks. Patients preferring expectant management were managed as outpatient without intervention for 2 weeks after which repeat USG was done to ascertain complete miscarriage. Failed expectant management patients underwent planned surgical uterine evacuation. Emergency admission and evacuation was done, if symptomatic during waiting period. Success rate and complications like emergency evacuation, vaginal bleeding, abdominal pain, limitation of physical activity and patient satisfaction were assessed and compared in subgroups of anembryonic pregnancy, early fetal demise and incomplete miscarriage. Statistical analysis was done by chi-square test.

Results: Incomplete miscarriage group had highest success rate of $88.46 \%$. followed by anembryonic pregnancy $(72.5 \%)$ and EFD (47.83\%) p value $=0.007$. Complication rate was highest in EFD, followed by anembryonic and the least in incomplete miscarriage all of which was statistically significant except vaginal bleeding.

Conclusions: Expectant management should be offered as first line choice for all types of early pregnancy miscarriages. Proper selection of case as to type of miscarriage especially incomplete miscarriage and selected cases of anembryonic pregnancy and EFD ensures higher success rate with lesser complications. Reserving medical and surgical management for unsuitable/failed cases.

Keywords: Anembryonic pregnancy, Early fetal demise, Early pregnancy miscarriage, Expectant management, Incomplete miscarriage

\section{INTRODUCTION}

Surgical uterine evacuation; for decades, is considered the gold standard management in spontaneous pregnancy miscarriage being definitive with immediate cure. ${ }^{1-3}$ But being an invasive procedure; surgical uterine evacuation has also reported complications which includes hospitalization, anaesthesia, perforation, excessive bleeding, re-evacuation, sepsis, intrauterine adhesions and subfertility, which led to research on non-surgical methods of management. ${ }^{4-6}$ Medical management of spontaneous miscarriage has demonstrated safety and efficacy with comparable success rates with advantage of being non-invasive..$^{5-7}$ The acceptability of medical methods is still questioned by the choice of preferred drug, optimal dosage and need for re-admission due to 
excessive symptoms. ${ }^{5,8,9}$ The last two decades have witnessed a change in trend, with different studies proving the effectiveness of expectant management of miscarriages which follows the natural history of miscarriage and it is an attractive option to many women who wish to avoid all forms of medical and surgical interventions in treatment of miscarriage. ${ }^{10-13}$ Expectant management is relatively inexpensive and safe, but the limiting factor is high failure rate and complications. ${ }^{14-17}$ This has led investigators to study about different selection criteria which could reliably predict the likelihood of a complete spontaneous resolution of pregnancy. ${ }^{18-23}$ Proper selection of cases for expectant management of early pregnancy miscarriages could result in higher success rate with lesser complications thereby increasing its acceptability. ${ }^{20-23}$ This study was to investigate difference in success rate and complication in expectant management of early pregnancy miscarriages with regard to the type of miscarriage: anembryonic pregnancy, early fetal demise and incomplete miscarriage.

The aim of this study was to study the difference in success rate and complications in expectant management in each of the three groups of early pregnancy miscarriages: anembryonic pregnancy, early fetal demise and incomplete miscarriage.

\section{METHODS}

The prospective observational study conducted in tertiary care centre for 3 years included 107 patients with USG confirmed pregnancy miscarriage of less than 13 weeks gestational age.

\section{Inclusion criteria}

\section{The USG criteria for inclusion in the study $y^{10,18,24,25}$}

- Anembryonic pregnancy: Gestational sac mean diameter of at least $25 \mathrm{~mm}$ with no embryonic/extra embryonic structures present)

- $\quad$ Early fetal demise (EFD): CRL of at least $7 \mathrm{~mm}$ with no cardiac activity, or no change in size on weekly serial scanning

- Incomplete miscarriage: Disrupted endometrial echo measuring more than $15 \mathrm{~mm}$ measured in the anteroposterior plane, with the presence of heterogeneous and irregular tissues.

\section{Exclusion criteria}

- Patients with gestational age more than13 weeks, severe vaginal bleeding, severe abdominal pain, hemodynamic instability at presentation, fever, chronic illness were excluded from the study.

Institutional ethical committee approval was obtained. Initial clinical examination and counselling were done regarding the different options of management of pregnancy miscarriages. On patient preference and written informed consent, a total $\mathrm{n}=107$ were allocated for expectant management. 7 patients lost follow-up. Of the remaining 100 patients there were anembryonic pregnancy $(n=51)$, Early fetal demise $(n=23)$ and incomplete miscarriage $(n=26)$. All patients were given Inj. Tetanus Toxoid and Anti D was given to Rh negative patients. Expectant management was done as outpatient without any intervention till spontaneous complete miscarriage was ascertained by repeat USG at the end of 2 weeks. Patients were counselled regarding the expected symptoms and to report in case of untoward symptoms of severe bleeding per vaginum, severe abdominal pain, fever or discharge per vaginum and a pamphlet explaining the same was given during the waiting period. Antibiotic prophylaxis was given to all patients.

Criteria for complete miscarriage: USG endometrial thickness of less than $15 \mathrm{~mm}$ measured in the anteroposterior plane associated with the cessation of heavy bleeding and pain. ${ }^{10,18,24,25}$

Patients with failed expectant management, underwent planned surgical uterine evacuation (dilatation and evacuation). Emergency admission and surgical evacuation was done, if symptomatic/indicated in the waiting period. Patients were followed up for 6 more weeks clinically and by urine pregnancy test.

In the three subgroups of anembryonic pregnancy, early fetal demise and incomplete miscarriage; the following parameters were assessed and compared (1) Success rate (2) Vaginal bleeding-assessed by pictorial blood loss assessment chart (3) Abdominal pain-assessed by visual analogue scale (4) Need for emergency evacuation (5) Limitation of physical activity (questionnaire) and (6) Patient satisfaction (questionnaire).

\section{Statistical analysis}

Statistical analysis done by chi-square test.

\section{RESULTS}

The study group included a total of 100 patients; anembryonic pregnancy $(n=51)$, early fetal demise $(n=23)$ and incomplete miscarriage $(n=26)$. The three groups of anembryonic pregnancy, early fetal demise (EFD), incomplete miscarriage was comparable in relation to age, parity and gestational age Table 1 .

Comparison of the success rate between these three groups showed that incomplete miscarriage group had the highest success rate of $23 / 26(88.46 \%)$. Success rate in anembryonic pregnancy is $37 / 51(72.55 \%)$. EFD having the lowest success rate of $11 / 23(47.83 \%)$ Figure 1 ( $p$ value $=0.007$ ). Most of patients in all three groups had only mild bleeding. Moderate bleeding was experienced by $7 / 51(13.73 \%)$ of anembryonic pregnancy, 3/23 $(13.04 \%)$ of EFD and 5/26 (19.23\%) of incomplete 
miscarriages. The rate of severe bleeding was highest in EFD group 3/23 (13.04\%), followed by anembryonic group 2/51 (3.92\%). There was no episode of severe bleeding in incomplete miscarriage group Figure 2 (p value $=0.361$ ).

Table 1: Patient characteristics of study group.

\begin{tabular}{|llllll|}
\hline Type of miscarriage & Average age (years) & $\begin{array}{l}\text { Nulliparous } \\
(\%)\end{array}$ & $\begin{array}{l}\text { GA }<8 \\
\text { weeks }(\%)\end{array}$ & $\begin{array}{l}\text { GA 8-12 } \\
\text { weeks }(\%)\end{array}$ & $\begin{array}{l}\text { GA }>\text { 12 } \\
\text { weeks }(\%)\end{array}$ \\
\hline Anembryonic pregnancy $(\mathrm{n}=51)$ & $25.25 \pm 5.19$ & 62.75 & 31.37 & 45.1 & 23.53 \\
\hline Early fetal demise $(\mathrm{n}=23)$ & $25.65 \pm 4.47$ & 56.52 & 4.35 & 65.22 & 30.43 \\
\hline Incomplete miscarriage $(\mathrm{n}=26)$ & $24.76 \pm 4.77$ & 61.54 & 34.62 & 42.31 & 23.08 \\
\hline
\end{tabular}

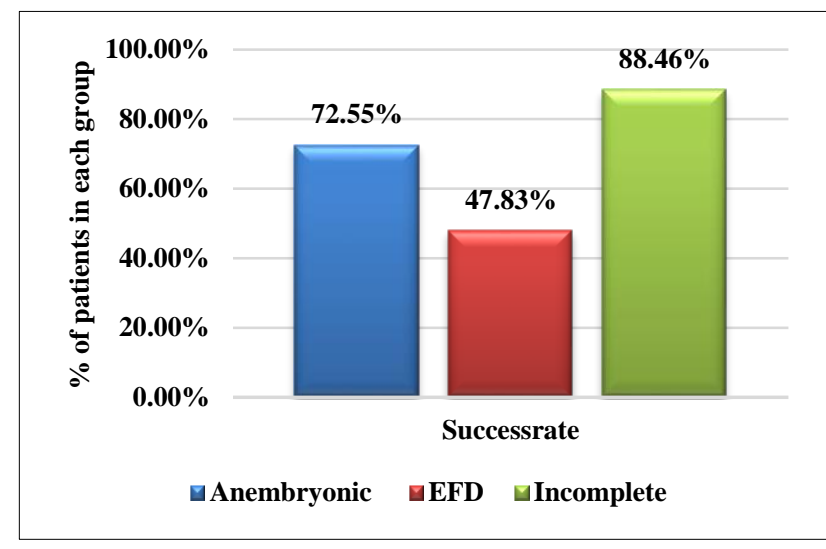

Figure 1: Comparison of success rate in 3 groups.

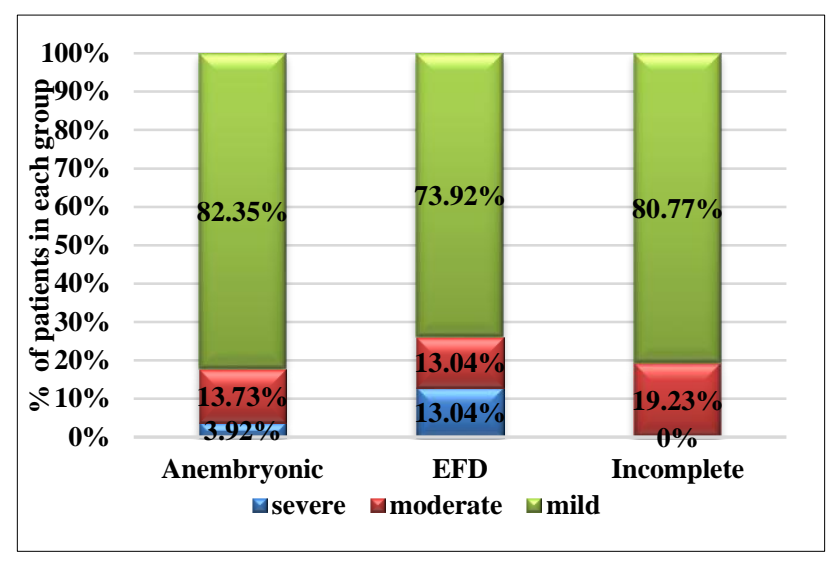

Figure 2: Comparison of bleeding in three groups.

Majority i.e., 15/23 (65.22\%) in EFD, 35/51 (68.62\%) in anembryonic pregnancy and 24/26 (92.30\%) in incomplete group experienced only mild pain. 13/51 (25.49\%) of anembryonic pregnancy, 5/23 (21.74\%) of EFD had moderate pain. Severe pain was experienced by $3 / 23(13.04 \%)$ of EFD, 3/51 (5.88\%) in anembryonic group and $2 / 26(7.69 \%)$ of incomplete miscarriage Figure 3 ( $\mathrm{p}$ value $=0.018$ ).

Rate of emergency evacuation was highest in EFD group $5 / 23(21.73 \%)$. followed by anembryonic group $4 / 51$
(7.84\%). There was no emergency evacuation in incomplete miscarriage group Figure $4(\mathrm{p}$ value $=0.047)$.

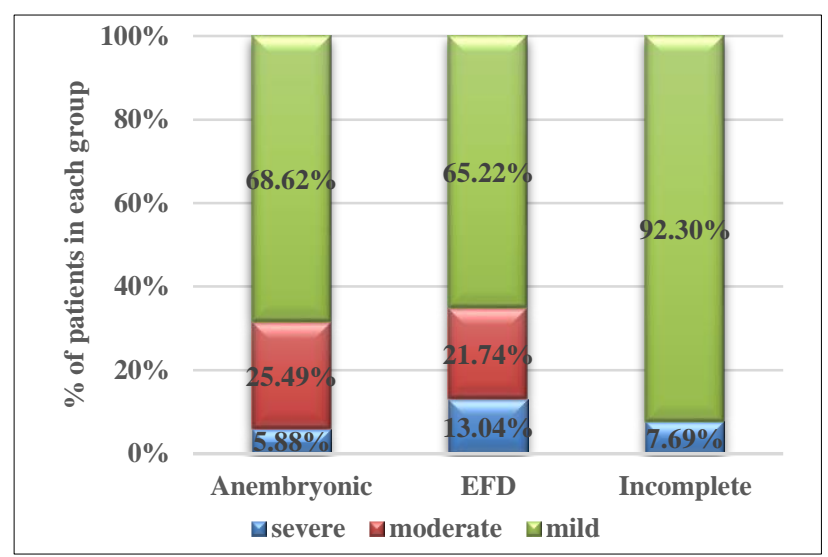

Figure 3: Comparison of pain in three groups.

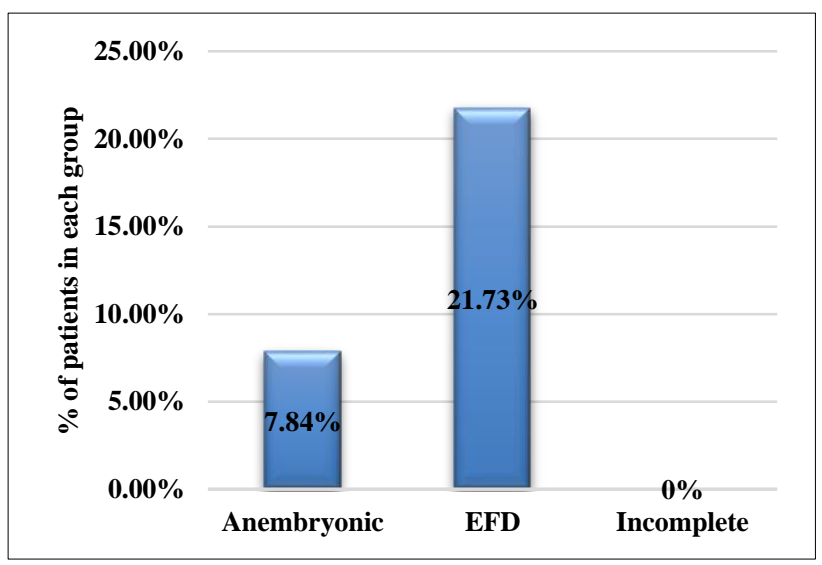

Figure 4: Emergency evacuation rates.

Physical activity was normal in majority of three groups. Higher limitation of physical activity was experienced in EFD group $8 / 23(34.78 \%)$ when compared to $11 / 51$ $(21.57 \%)$ and $2 / 26(7.69 \%)$ in anembryonic and incomplete groups respectively Figure 5 (p value $=0.007$ ).

Incomplete miscarriage group had a high patient satisfaction rate of $23 / 26(88.47 \%)$ followed by 
anembryonic pregnancy group 40/51 (78.50\%) and was least in EFD group i.e., 12/23 (47.83\%). Graph 6 (p value $=0.003$ ).

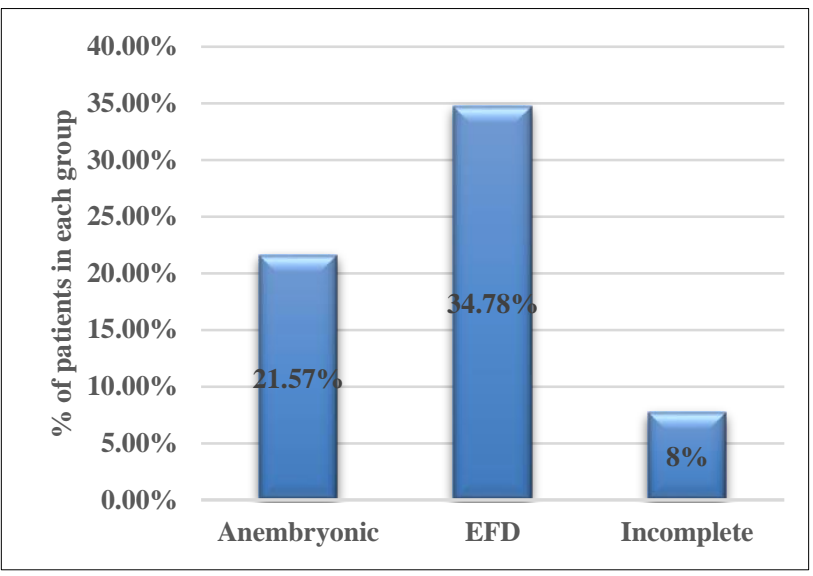

Figure 5: Limitation of physical activity.

Failure rate in patients with Gestational sac diameter more than $30 \mathrm{~mm}$ was $33.3 \%$ and that in patients with gestational sac $<30 \mathrm{~mm}$ was $30.7 \%$. Failure rate in patients with endometrial thickness $<20 \mathrm{~mm}$ was $10 \%$ and that in patients $>20 \mathrm{~mm}$ was $16.6 \%$. 18/61 nullipara ended in failure (29.5\%). 11/39 (28.2\%) of multipara ended in failure ( $\mathrm{p}$ value 0.05 ).

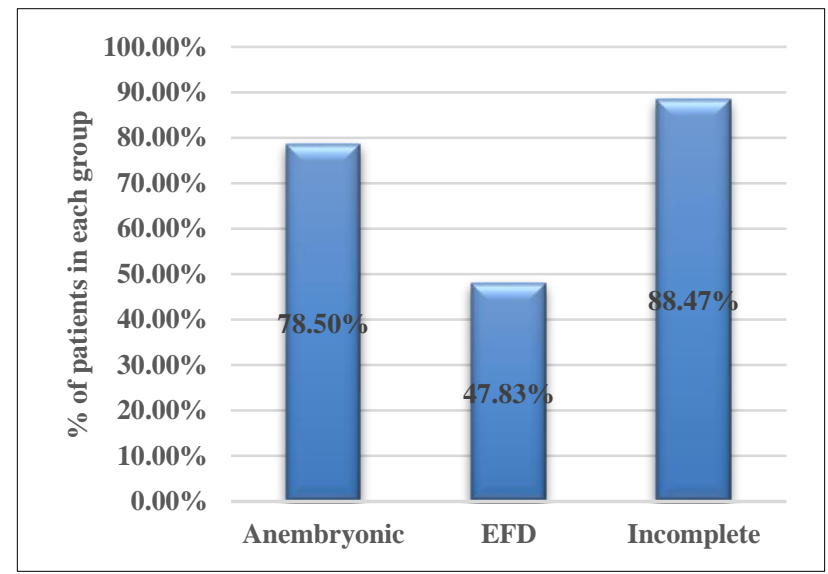

Figure 6: Patient satisfaction rate.

\section{DISCUSSION}

Advent of different studies in last two decades proving effectiveness of expectant management of miscarriages, has led to a change in trend in management of early pregnancy miscarriages moving forward from the gold standard management of surgical uterine evacuation and non-invasive medical management to include expectant management; which follows the natural history of miscarriage; avoiding all forms of medical and surgical interventions. ${ }^{1,2,10,11}$ It was demonstrated that using initial expectant management of miscarriage can reduce the number of surgical procedures required by $37 \% .^{17}$ Analysis of miscarriage management in Finland from
1998-2016 had shown clear trend towards conservative management, with surgical management of missed miscarriage declining from $70.9 \%$ to $11.2 \%$ and blighted ovum from $60.7 \%$ to $9.4 \% .^{16}$

The upcoming studies also proved the positive aspects of expectant management with comparable incidence of different complications for women managed expectantly $(1 \%-8 \%)$ and surgically $(2 \%-13 \%) .^{6-8,14}$ Few studies reported lesser incidence of pelvic infection (0-3\%) than surgical (0-10\%). ${ }^{9-11}$ Apart from proven better HQRL and cost effectiveness, long-term outcome on future pregnancy rate, miscarriage rate and the incidence of ectopic pregnancy after expectant management were also reassuring. ${ }^{12-15}$

But acceptability of expectant management did not rise up as a primary management option in miscarriage due to reports of failure rate between 10 and $75 \% .^{10,11,14}$ In this study also success rate of expectant management was higher for incomplete miscarriage 23/26 (88.46\%) followed by anembryonic pregnancy $37 / 51$ (72.55\%) and was $<50 \%$ (11/23) for early fetal demise (EFD) which was statistically significant with $\mathrm{p}$ value $=0.007$. This result is comparable with different published studies proving that type of miscarriage alone can be used as a predictor of successful expectant management with success rate for women with incomplete miscarriage always higher 79-100\%; than non-viable pregnancy $25-$ $84 \%$; following similar periods of expectancy. ${ }^{1,2,10,17}$

The severe pain and bleeding of a miscarriage may compel a woman to prefer operative treatment. ${ }^{6,7,10}$ In this study majority of patients had only mild pain and bleeding. None of the patients in incomplete miscarriage had severe bleeding. Whereas severe bleeding was reported in $2 / 51(3.92 \%)$ of anembryonic pregnancy and was highest in EFD group 3/23 (13.04\%). None required blood transfusion. Duration of bleeding was 8-12 days in incomplete miscarriage group and 10-14 days in anembryonic pregnancy and EFD group. This was not statistically significant; $\mathrm{p}$ value $=0.361$.

Similarly, in this study severe pain was low and comparable in incomplete miscarriage $2 / 26(7.68 \%)$ and anembryonic pregnancy $3 / 51 \quad(5.88 \%)$ and was comparatively higher in EFD 3/23 (13.04\%) which was again statistically significant with $\mathrm{p}$ value $=0.018$. This was comparable to study by Neilson et al and $\mathbf{J}$ Trinder et al (MIST Trial) which showed increased pain and vaginal bleeding for missed miscarriages than incomplete miscarriage. ${ }^{1,10}$

Significantly more unplanned admissions and unplanned surgical curettage occurred after expectant management than medical management and surgical management with a reported highest in missed miscarriage than incomplete miscarriage. ${ }^{10,11,17}$ In this study too, statistically significant ( $\mathrm{p}$ value $=0.047$ ) highest rate of emergency evacuation occurred in EFD group 5/23 (21.73\%); 
followed by anembryonic group 4/51 (7.84\%) with no emergency evacuation in incomplete miscarriage group.

Higher rate of limitation of physical activity $8 / 23$ $(34.78 \%)$ associated with EFD compared to $11 / 51$ $(21.57 \%)$ and $2 / 26(7.69 \%)$ in anembryonic and incomplete groups respectively; was due to increased bleeding and pain experienced in this group ( $p$ value $=0.007$ ).

When incomplete miscarriage and anembryonic pregnancy groups had a comparable patient satisfaction rate of $23 / 26(88.47 \%)$ and $40 / 51(78.50 \%)$ respectively, more than half of the patients in EFD group i.e. 12/23 $(52.17 \%)$ were dissatisfied with their expectant management because of higher incidence of adverse outcome like treatment failure, increased bleeding and pain, limitation of physical activity and emergency evacuation $(\mathrm{p}$ value $=0.003)$.

One of the difficulties with expectant management of miscarriages is the lack of selection criteria which could predict the likelihood of a complete spontaneous resolution of pregnancy. ${ }^{10,17,20}$ This has led to the research for predictors for successful expectant management with lesser complications. ${ }^{18-23}$ Vaginal bleeding at presentation, maternal age and early gestational age were found positively correlated to successful expectant management. ${ }^{18-21}$ Diagnosis of incomplete miscarriage at primary scan reported higher success rates than those that included only women with missed or anembryonic pregnancy loss. ${ }^{10,11}$ Even though increased waiting period increased success rate, the 'two-week' rule for the expectant management had highest success rates of spontaneous resolution at 2 weeks according to the type of miscarriage - $71 \%$ for incomplete miscarriage, $53 \%$ for empty sac and $35 \%$ for missed miscarriage. ${ }^{7-10,18}$

Colour Doppler imaging of the intervillous space and the uterine artery blood flow and several maternal serum markers like serum HCG, progesterone, inhibin A, inhibin pro $\alpha-\mathrm{C}$ RI and cervical nitric oxide has been studied as predictors of successful expectant management. ${ }^{20-23}$ 'Logistic regression model' by Neilson et al and 'Mathematical model' by Casikar et al were successfully developed and tested by including multiple predictors for successful expectant management. ${ }^{20,21}$

NICE Guideline 2019 and ACOG practice bulletin of 2018 has included expectant management as a reasonable first line option in all cases of miscarriages. There is no added advantage with medical management over expectant management in incomplete miscarriage due higher reported success rate of expectant management (80\% in 3 days). So ACOG 2018 states that medical management should not be routinely offered to incomplete miscarriages in the first trimester. ${ }^{25}$ Even in anembryonic pregnancy and EFD, expectant management should be discussed as a first option in gestational age $<10$ weeks. Medical management is less likely to be successful after failed expectant management, where we have to opt for surgical evacuation. ${ }^{9,24,25}$ In anembryonic pregnancy and EFD advantage of medical management is that it offers faster and more predictable commencement of bleeding, has fewer emergency admissions and fewer surgical evacuation $(20 \%$ with medical versus $30 \%$ with expectant) even though duration of bleeding is comparable for both methods. But here again expectant management is more cost effective compared to medical management. Therefore, medical and surgical management may be more effective second line option for the management of anembryonic gestation and EFD, depending on informed choice. Medical management as first line option for anembryonic pregnancy and EFD should be offered only on patient preference and ultrasound gestational age $>10$. weeks. ${ }^{24,25}$ Only advantage of surgical management of miscarriages is a predictable start and end point and lesser follow-up needed. And so; indication for surgical management apart from patient preference, severe bleeding/pain, hemodynamic instability and failed expectant/medical management are USG gestational age $>10$ weeks, USG tissue diameter $>50 \mathrm{~mm}$ and suspected GTD. ${ }^{24,25}$

Limitations of this study were that equal number of patients could not be allotted in each group for expectant management as patients were allotted based on their availability and preference after counselling. Even though comparison between the three groups of incomplete miscarriage, anembryonic pregnancy and early fetal demise for expectant management could be made, each group could not be compared with surgical or medical management. Infection rate could not be assessed as patients were put on antibiotics.

\section{CONCLUSION}

Expectant management should be offered as first line management of early pregnancy miscarriages in developing countries also. Proper selection of patients with the available resources such as ultrasound, could help tackle the anticipated problems of lesser available facilities, complications and follow up required with the added advantage of cost effectiveness.

Type of miscarriage at diagnosis could be used to select a patient suited for expectant management of miscarriages. With expectant management, incomplete miscarriage had the highest success rate with lesser complications of severe vaginal bleeding/abdominal pain and emergency evacuation with lesser limitation of physical activity and higher patient satisfaction rate. Early fetal demise group had higher failure rate with higher rate of complications and anembryonic pregnancy having failure rate and complications slightly higher than incomplete abortion but much lesser than early fetal demise. With further research to develop an easier clinical scoring system; with special score to type of miscarriage for prediction of successful expectant management of first trimester miscarriage; could prove a long way for acceptance of 
expectant management of early pregnancy miscarriage as an easier, most natural, cost effective and successful method with lesser complications.

\section{Recommendations}

\section{Future research}

Simplified models of predictors of successful expectant management suited to developing countries could be developed compiling more of clinical data like age, gestational age, symptoms at presentation, ultrasound criteria with special reference to type of miscarriage.

\section{ACKNOWLEDGMENTS}

Authors would like to thank Mrs. Arya S. Nath, statistician, department of community medicine, MES Medical College, Perinthalmanna, Kerala, India for the help in statistical analysis.

Funding: No funding sources

Conflict of interest: None declared

Ethical approval: The study was approved by the Institutional Ethics Committee

\section{REFERENCES}

1. Nielsen S, Hahlin M. Expectant management of firsttrimester spontaneous abortion. The Lancet. 1995;345(8942):84-5.

2. Luise C, Jermy K, May C, Costello G, Collins WP, Bourne TH. Outcome of expectant management of spontaneous first trimester miscarriage: observational study. BMJ. 2002;324(7342):873-5.

3. Sagili H, Divers M. Modern management of miscarriage. The Obstet Gynaecol. 2007;9(2):102-8.

4. Zhang J, Gilles JM, Barnhart K, Creinin MD, Westhoff C, Frederick MM, et al. A comparison of medical management with misoprostol and surgical management for early pregnancy failure. N Engl J Med. 2005;353(8):761-9.

5. Chung TK, Lee DT, Cheung LP, Haines CJ, Chang AM. Spontaneous abortion: a randomized, controlled trial comparing surgical evacuation with conservative management using misoprostol. Fertil Steril. 1999;71(6):1054-9.

6. Nanda K, Lopez LM, Grimes DA, Peloggia A, Nanda G. Expectant care versus surgical treatment for miscarriage. Cochrane Database Systematic Reviews. 2012;3:CD003518..

7. Al-Ma'ani W, Solomayer EF, Hammadeh M. Expectant versus surgical management of firsttrimester miscarriage: a randomised controlled study. Arch Gynecol Obstet. 2014;289(5):1011-5.

8. Rafi J, Khalil H. Expectant management of miscarriage in view of NICE Guideline 154. J Preg. 2014;2014.

9. Bagratee JS, Khullar V, Regan L, Moodley J, Kagoro H. A randomized controlled trial comparing medical and expectant management of first trimester miscarriage. Human Reprod. 2004;19(2):266-71.

10. Trinder J, Brocklehurst P, Porter R, Read M, Vyas S, Smith L. Management of miscarriage: expectant, medical, or surgical? Results of randomised controlled trial (miscarriage treatment (MIST) trial). BMJ. 2006;332(7552):1235-40.

11. Sotiriadis A, Makrydimas G, Papatheodorou S, Ioannidis JP. Expectant, medical, or surgical management of first-trimester miscarriage: a metaanalysis. Obstet Gynecol. 2005;105(5):1104-13.

12. Newbatt E, Beckles Z, Ullman R, Lumsden MA. Ectopic pregnancy and miscarriage: summary of NICE guidance. BMJ. 2012;345.

13. Blohm F, Hihlin M, Nielsen S, Milson I. Fertility after a randomised trial of spontaneous abortion managed by surgical evacuation or expectant treatment. The Lancet. 1997;349(9057):995.

14. Wieringa-de Waard M, Hartman EE, Ankum WM, Reitsma JB, Bindels PJ, Bonsel GJ. Expectant management versus surgical evacuation in first trimester miscarriage: health-related quality of life in randomized and non-randomized patients. Human Reprod. 2002;17(6):1638-42.

15. You JH, Chung TK. Expectant, medical or surgical treatment for spontaneous abortion in first trimester of pregnancy: a cost analysis. Human Reprod. 2005;20(10):2873-8.

16. Linnakaari R, Helle N, Mentula M, Bloigu A, Gissler $\mathrm{M}$, Heikinheimo $\mathrm{O}$, et al. Trends in the incidence, rate and treatment of miscarriage-nationwide register-study in Finland, 1998-2016. Human Reprod. 2019;34(11):2120-8.

17. Wieringa-de Waard M, Vos J, Bonsel GJ, Bindels PJ, Ankum WM. Management of miscarriage: a randomized controlled trial of expectant management versus surgical evacuation. Human Reprod. 2002;17(9):2445-50.

18. Sairam S, Khare M, Michailidis G, Thilaganathan B. The role of ultrasound in the expectant management of early pregnancy loss. Ultrasound Obstet Gynecol. 2001;17(6):506-9.

19. Casikar I, Lu C, Reid S, Condous G. Does symptomatology at presentation correlate with successful expectant management of first trimester miscarriage: A prospective observational study. Aust New Zealand J Obstet Gynaecol. 2013;53(2):178-83.

20. Nielsen S, Hahlin M, Odén A. Using a logistic model to identify women with first-trimester spontaneous abortion suitable for expectant management. BJOG: An Int J Obstet Gynaecol. 1996;103(12):1230-5.

21. Casikar I, Lu C, Reid S, Condous G. Prediction of successful expectant management of first trimester miscarriage: development and validation of a new mathematical model. Aust New Zealand J Obstet Gynaecol. 2013;53(1):58-63.

22. Casikar I, Lu C, Oates J, Bignardi T, Alhamdan D, Condous G. The use of power Doppler colour scoring to predict successful expectant management 
in women with an incomplete miscarriage. Human Reprod. 2012;27(3):669-75.

23. Memtsa M, Jauniaux E, Gulbis B, Nyrhinen NC, Jurkovic D. Maternal serum markers in predicting successful outcome in expectant management of missed miscarriage. Reprod Biomed Online. 2017;34(1):98-103.

24. Webster K, Eadon H, Fishburn S, Kumar G. Ectopic pregnancy and miscarriage: diagnosis and initial management: summary of updated NICE guidance. BMJ. 2019:367.

25. American College of Obstetricians and Gynecologists. ACOG practice bulletin no. 200: early pregnancy loss. Obstet Gynecol. 2018;132(5):e197-207.

Cite this article as: Sajan RKK, Mumtaz $\mathrm{P}$, Chandrika CV, Vahab A, Imrana HS. Expectant management of incomplete miscarriage, anembryonic pregnancy and early fetal demise: a comparative study. Int J Reprod Contracept Obstet Gynecol 2020;9:3144-50. 